\title{
The hydro-seeding and concrete anchors as a method for preventing damage to district heating network by local landslides
}

\author{
Stanislav Chicherin ${ }^{1, *}$ Lyazzat Junussova ${ }^{2}$, and Timur Junussov ${ }^{2}$ \\ ${ }^{1}$ Omsk State Transport University, Omsk, Russia \\ ${ }^{2}$ Almaty University of Power Engineering and Telecommunications, Almaty, Kazakhstan
}

\begin{abstract}
To prevent rain from eroding the sides of the trench we have developed a method of spraying them with hydro-seed. The homemade solution contains water, soil, mulch and a special blend of local grass seed. The mixture containing the blend of seeds enhances the soil to give it some strength and minimize the erosion. Another option is using concrete anchors instead of steel ones, which are supposed to increase the rigidity of a district heating (DH) network. The paper further visualizes the process with the materials required for each step. We constructed the equation in order to estimate net present value depending on the capital costs of the construction, the time of the cash flow, and the discount rate. In case of concrete anchors, the NPV of the project is negative. However, in case of hydro-seeding, the income provided by avoiding penalties becomes bigger than initial costs in the very first year of the project life span. From the comparison of two NPV profiles, the model combining the concrete anchors and the hydroseeding can save up to $20 \%$ of investments compared to the conventional DH line. Results show that although then capital costs are increased by up to $24 \%$, investment payback for DH network can be reduced to 12 years while life span can be increased by up to 30 years.
\end{abstract}

\section{Introduction}

With the continuous development and increasing applications of district heating (DH), a heat supply interruption has been the focus of multiple studies in the last few years [1,2]. Shan et al. [3] consider the insufficiency of heating supply ability due to leakages. Even in the DH industry a decentralized heat pump is now a common solution to raise the excess heat temperature $\left(30^{\circ} \mathrm{C}\right)$ up to the network level $\left(65^{\circ} \mathrm{C}\right)$ or to recover heat directly via a heat distribution system with supply temperature of $30^{\circ} \mathrm{C}$ and electric water heaters for DHW preparation $[4,5]$. Each location where a heat pump is implemented will not need to connect its specific stock of buildings to the DH network. This discourages developers from a $\mathrm{DH}$ system expansion reducing network construction.

Estimating greenhouse gas (GHG) emissions is a common method applicable to both assessing the replacement conventional heating systems with $\mathrm{DH}-$ supplied heat [6] and an ordinary railway sleeper with an eco-concrete one [7]. Thomas et al. [8] prove that recycled concrete aggregates produced from waste concrete are a sustainable alternative to natural crushed stone aggregates when the mechanical or durability properties are considered. Segmental joints between concrete segments act as a weak link in the tunnel lining both in terms of mechanical stress (due to the lower stiffness and strength compared to the main segments) and the lifetime issues (high risk of water/gas leakage) [9]. However, concrete anchors had never before been applicable in DH projects in Russia.

The economic performance of replacing traditional construction methods, such as steel anchors or concrete surface trenches, is studied using cash flow and cost metrics. In Ref. [7] a simplified life cycle assessment method was applied to compare GHG emissions and an instrumental treatment as well as a physical performance test were carried out to identify the protection mechanism between the agent and concrete along with field tests. In future the same evaluation will explore conditions for profitability of transferring new technologies to the Russian construction practice.

\section{Materials and methods}

Of the $5 \mathrm{~km}$ length of the river diversion for Om' river about two third of it is covered with trees to protect embankment. Now other third of it is covered in an unexpected material - grass. The first step is workers going to make a mixture in order to protect the slopes. To protect the river bank, the team utilizes a super-fast technique called hydroseeding that produces grass in just three-month time. They start with a liquid mixture with water, mulch, fertilizer and two varieties of Brazilian grass seed. They use two different seeds because one growths straight up while the other spreads out for maximum coverage. The process is like a painting and the color shows you which area you have already pours.

\footnotetext{
Corresponding author: man csv@hotmail.com
} 
During the spring season the Om' river can rise 1 meter in just a few hours [10]. So this grass is critical in preventing massive landslides. And to make sure grass stays put there is one final step. Here comes erosion control mat. This mat will provide a mold for the grass to grow into a tight weave keeping the river bank in place for good. But permanently changing the course of the
Om' river requires a lot of erosion mats. We used typical NPV equation in order to estimate net present value (NPV) depending on the capital costs (CC) of the construction, the time of the cash flow (t), and the discount rate $(\mathrm{E})$.

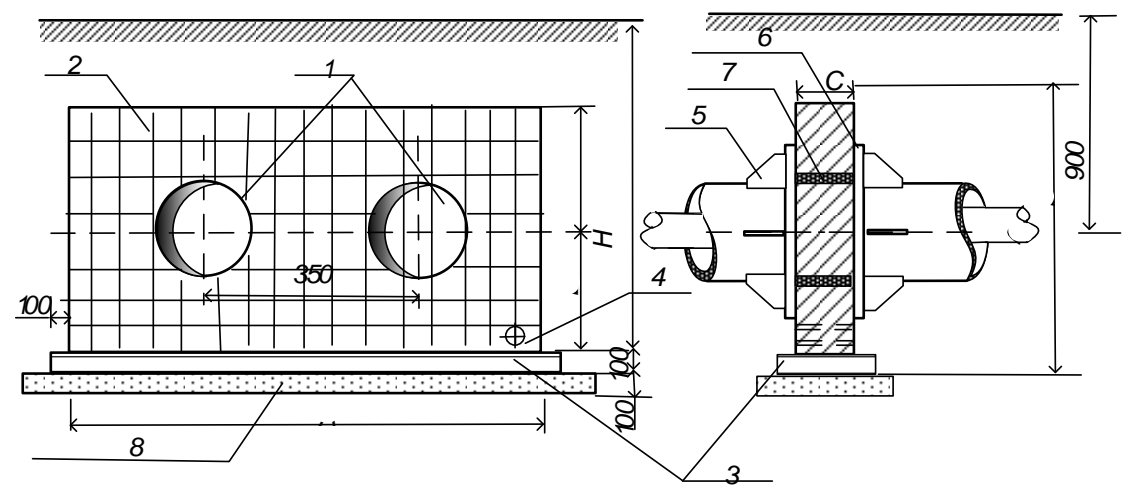

Fig. 1. The anchor detail (1) Air space, (2) reinforced concrete anchor, (3) concrete base, (4) water drain trough, (5) steel support, (6) $1 / 2$ " thick steel end plate (welded to steel support (5)), (7) threaded s.s. stud, (8) sand base.

\section{Results and Discussion}

\subsection{The hydro-seeding}

To prevent rain from eroding the sides of the trench the team will spray the hills with hydro-seed. The homemade solution starts with water, soil, mulch and a special blend of local grass seed. This mixture, this blend of seeds that will actually enliven the soil give it some strength and minimize the erosion. Finally, they add a natural fertilizer. The team has to spray hydro-seed over 450,000 of square meters of land. Workers use a hose with 18 psi of pressure spreading over a ton of hydroseed in just 30 minutes. The crew has just four months to complete all the hydroseeding before Omsk winter sets in and grass walkthrough. That grass planted on that hill will keep the slope in place, minimize erosion and let the hot water flow from the plant all the way down towards the city without an interruption. This is the one of the final steps in a 50-year effort to rein in a river. An interruption is the main issue that influences the operational availability of DH [11].

When a dimension of a damaged section is DN500 or above, the repair time in case of larger steel anchors tends to be longer [12]. The pipe movements are insignificant when it is DN500 or below, while they are becoming larger as the rigidity decreases. Hence, proper design of anchors between pipe guides can efficiently reduce the repair time of fault components [13].

\subsection{Concrete anchors}

The concrete anchors instead of steel ones to increase the rigidity of a DH network. Figure 1 further visualizes the process with the materials required for each detail.

Once in the trench the positioning of an anchor is critical for the assembling. Once that is done they will take brand new massive DN800 pipe and insert it into the pre-cast hole. The team drops a pipe section 10 meters down to connect it to an anchor. Because the trench is narrow with horizontal supports inserting the pipe is a tough task. Moreover, because the steel struts keeping the tunnel or trench open pipe is not going normally. They deep it down and get it through. To clear the pipe, they lower it with a slope of 0.002 . The angle of the pipes reduces the clearance to less than a few inches. The circumference of this concrete circle is so tight that the steel pipe is wedged on a bottom. Locking an each piece of rebar to the one below it so when the concrete comes, it will not knock it out place (fig. 2). 


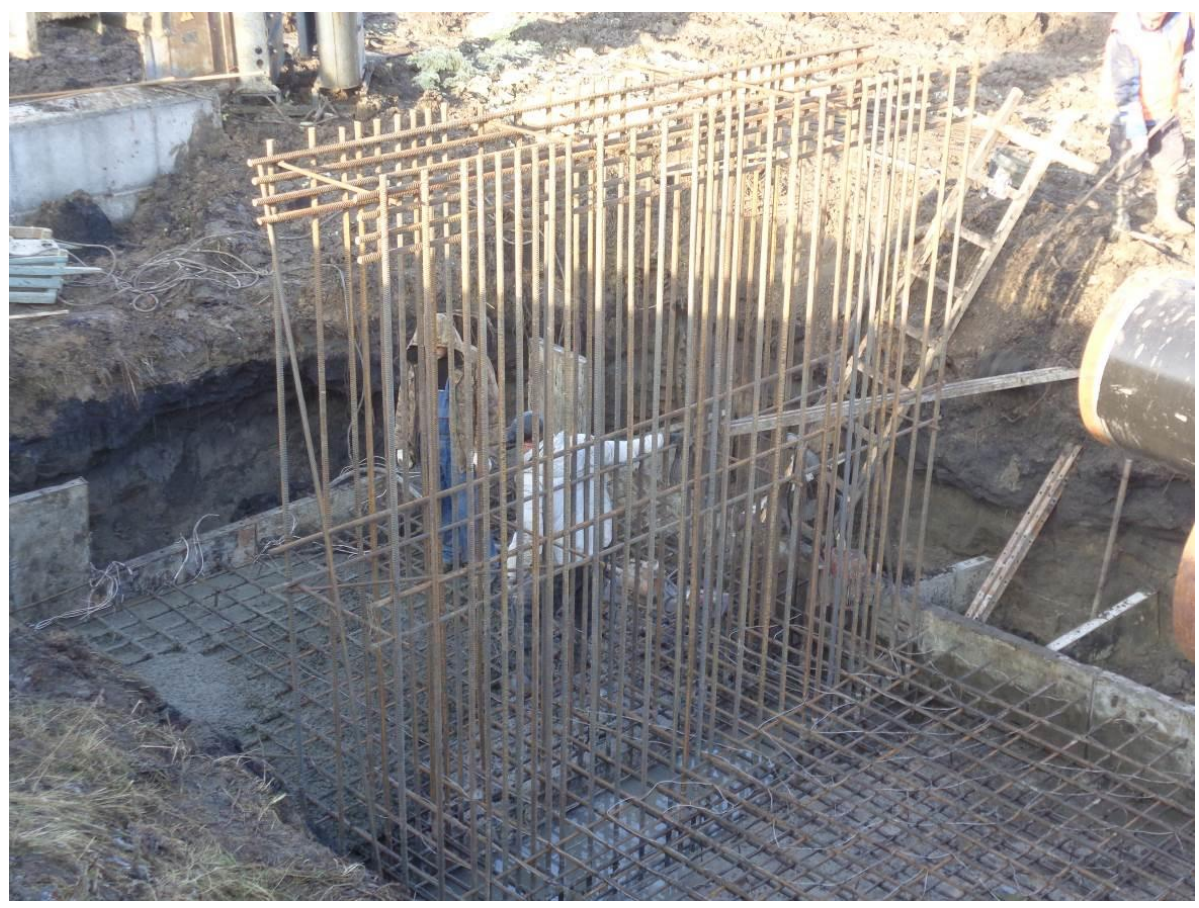

Fig. 2. All the rebar is laid out which means that this entire anchor is ready to be covered in concrete.

They've got just 6 hours to unload over six tons of concrete to finish the anchor. Placing the stream of concrete is a team effort by the men on a deck and a boom operator above. Using tons of concrete and a dense mesh of rebar for an anchor may seem like overkill but it is not. Because each material has its own unique strength concrete performs beautifully under compressive force, perfect for something like a column. But use it to span an anchor and forces of tension will tear it apart. But rebar is great at the standing tension. This stuff is almost impossible to rip apart. So while rebar is inside a concrete you get an anchor that cannot be crushed and will not rip. In future, steel fiber reinforced concrete [9] may substitute the traditional rebar in terms of maintained bearing capacity and improved cracking control, but it is hardly possible now. Just hours after the pour concrete is leveled and smoothed an anchor is done. The time of solidifying depends on water/cement ratio, cement content in concrete and percentage replacement of coarse aggregate, if any additives are included [14].

Just minutes after it mixed concrete gets shot up a bucket to fill the volume of 23 remaining anchors. But before that can happen the rebar columns must be fully enclosed in a formwork. Carpenters use clamps to build up the entire structure with panels. They get a piece in place, lock it with the clamps and move to the next side of an anchor. Then they are going to pull both sides together and squeeze it. All the cracks get flush and do not leak any concrete. The pour begins. 20 tonnes of concrete push at every seam. It is popped up 10 meters right now. They got a pressurized hose all way from a bottom coming up here. The crew must constantly jockey the hose around to prevent pressure build up. In Ref. [7] the surface protection agent with an anti-aging feature showed a chance of increasing lifespan of the concrete item and the use of alternative materials, such as furnace slag, reduced the concrete consumption by more than $20 \%(\mathrm{w} / \mathrm{w})$. Before these guys can clock out, there is one final critical step.

\subsection{Technical feasibility}

The concrete anchors instead of steel ones increase the rigidity of a DH network. The NPV when (a) the hydroseeding is projected can also be negative (but never here) when the incomes supplied by avoiding penalties becomes lower than funds consumed by the construction as it is the case for (b) the concrete anchors. Although (b) the concrete anchors and (a) the hydro-seeding have almost the same NPV profiles for the very begin, there is a very significant difference on their payback time (compare no payback time and 0 years). The NPV, which is the difference of cash flow and capital costs, may not need to be exactly equal to the values indicated in Table 1, but close. 
Table 1. Financial assumptions.

\begin{tabular}{|c|c|c|c|c|c|c|}
\hline \multirow[b]{2}{*}{ Year } & \multicolumn{3}{|c|}{ Hydro-seeding } & \multicolumn{3}{|c|}{ Concrete anchors } \\
\hline & Costs (USD) & $\begin{array}{c}\text { Cash flow } \\
\text { (USD) }\end{array}$ & $\begin{array}{l}\text { Net present value } \\
\text { (USD) }\end{array}$ & Costs (USD) & $\begin{array}{c}\text { Cash flow } \\
\text { (USD) }\end{array}$ & Net present value (USD) \\
\hline 2020 & 857.00 & 1756.00 & 606.33 & 888.00 & 0.00 & -888.00 \\
\hline 2021 & 300.00 & 1256.00 & 1178.56 & 300.00 & 0.00 & -1188.00 \\
\hline 2022 & & 756.00 & 1616.06 & & 0.00 & -1188.00 \\
\hline 2023 & & 256.00 & 1739.51 & & 0.00 & -1188.00 \\
\hline 2024 & & -244.00 & 1641.45 & 200.00 & 0.00 & -1188.00 \\
\hline 2025 & & -744.00 & 1392.29 & & 0.00 & -1188.00 \\
\hline 2026 & & -1244.00 & 1045.11 & & 0.00 & -1188.00 \\
\hline 2027 & & -1744.00 & 639.51 & & 0.00 & -1188.00 \\
\hline 2028 & & & & & 0.00 & -1188.00 \\
\hline 2029 & & & & & 0.00 & -1188.00 \\
\hline 2030 & & & & & 0.00 & -1188.00 \\
\hline Total & 1157.00 & 48.00 & 639.51 & 1388.00 & - & -1188.00 \\
\hline
\end{tabular}

\section{Conclusions}

With every meter the crew is one step closer to delivering heat directly to midtown Omsk. The way which it is delivered will be radically transformed. The city lives off its ability for hot water to move across it and to it. In 5 years this massive DH overhaul may be complete with anchors and hydroseeding moving heat faster and more efficiently than ever. Omsk city is without a doubt unlike any other place in Siberia. And when people come to visit this town they are shocked by how citizens live. From the comparison of NPV profiles, the model with (b) the concrete anchors and (a) the hydro-seeding can save up to $20 \%$ of investments than conventional DH line depending on the funds collected from avoiding fines and repairs. Analysis was carried out at the same discount and interest rate levels. Results show that although capital costs are increased by up to $24 \%$, investment payback for $\mathrm{DH}$ network can be reduced to 12 years while lifespan can be increased to 30 years.

\section{References}

1. S. Zhou, Z. O'Neill, and C. O'Neill A review of leakage detection methods for district heating networks, Appl. Therm. Eng. 137, 567-574 (2018)

2. S. Chicherin, L. Junussova, T. Junussov, Minimizing the supply temperature at the district heating plant - dynamic optimization. E3S Web of Conferences 118, 02004 (2019)

3. X. Shan, P. Wang, W. Lu, The reliability and availability evaluation of repairable district heating networks under changeable external conditions, Appl. Energy 203, 686-695 (2017)

4. L. R. Junussova, S. K. Abildinova, M. B. Aliyarova, S. V. Chicherin, and T. J. Junussov, The means to improve water treatment and to enhance power engineering performance of the water source heat pump, Energ. Proc. CIS High. Educ. Institutions Power Eng. Assoc. 61, 372-380 (2018)

5. J. Vivian, G. Emmi, A. Zarrella, X. Jobard, D. Pietruschka, M. De Carli, Evaluating the cost of heat for end users in ultra low temperature district heating networks with booster heat pumps, Energy 153, 788-800 (2018)

6. L. Björnebo, S. Spatari, P. L. Gurian A., Greenhouse gas abatement framework for investment in district heating, Appl. Energy 211, 1095-1105 (2018)

7. C.-K. Lee, J.-Y. Lee, I.-W. Lee, Y.-K. Kim, GHG mitigation of railway concrete products using ecoconcrete and surface protection agent, Constr. Build. Mater. 186, 1154-1160 (2018)

8. J. Thomas, N. N. Thaickavil, P. M. Wilson, Strength and durability of concrete containing recycled concrete aggregates, J. Build. Eng. 19, 349-365 (2018)

9. C. Gong, W. Ding, K. M. Mosalam, S. Günay, and K. Soga, Comparison of the structural behavior of reinforced concrete and steel fiber reinforced concrete tunnel segmental joints, Tunn. Undergr. Sp. Technol. 68, 38-57 (2017)

10. S. V. Chicherin, Comparison of a district heating system operation based on actual data - Omsk city, Russia, case study, International Journal of Sustainable Energy 38 (6), 603-614 (2018)

11. L. R. Junussova, S. V. Chicherin, Improving a water treatment and a heating performance of the water-towater heat pump: misallocation and available solutions, IOP Conference Series: Earth and Environmental Science 288, 012092 (2019)

12. M. Badami, A. Fonti, A. Carpignano, D. Grosso, Design of district heating networks through an integrated thermo-fluid dynamics and reliability modelling approach, Energy 144, 826-838 (2018)

13. S. Chicherin, A. Volkova, E. Latõšov, GIS-based optimisation for district heating network planning, Energy Procedia 149, 635-641 (2018)

14. L. Cao, C. Liu, H. Tian, D. Jia, D. Wang, Y. Xu, J. Guo, Absorption interaction between cement 
hydrates minerals with fluid loss additive investigated by fluorescence technique, Constr. Build. Mater. 223, 1106-1111 (2019) 